(C) American Chemical Society, J. Am. Chem. Soc., Supporting Info Page S-1

\title{
MCM-48-Like Large-Mesoporous Silicas with Tailored Pore Structure: Facile Synthesis Domain in a Ternary Triblock Copolymer-Butanol-Water System
}

\author{
Tae-Wan Kim, Freddy Kleitz, ${ }^{\ddagger}$ Blain Paul and Ryong Ryoo*
}

National Creative Research Initiative Center for Functional Nanomaterials, Department of

Chemistry (School of Molecular Science-BK21), Korea Advanced Institute of Science and

Technology, Daejeon, 305-701 Republic of Korea.

\footnotetext{
* Correspondence should be addressed to Prof. R. Ryoo (E-mail: rryoo@kaist.ac.kr).

Present address: Department of Chemistry, Université Laval, St Foy, Quebec, G1K 7P4, Canada
} 
(C) American Chemical Society, J. Am. Chem. Soc., Supporting Info Page S-2

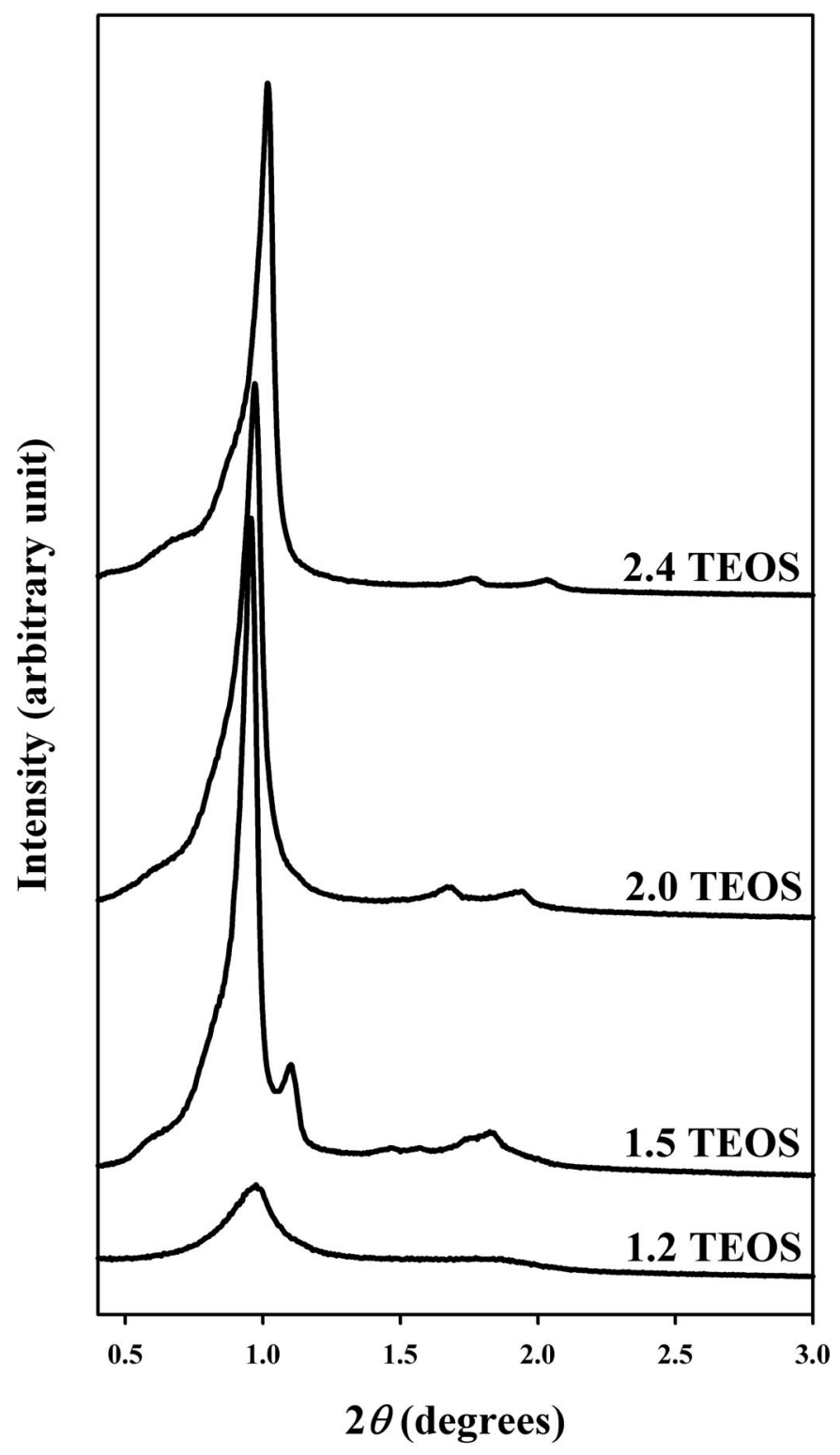

Figure S1 HRXRD patterns for the mesostructured silica materials obtained using 0.017

P123: $x$ TEOS:1.7 BuOH:1.83 HCl:195 $\mathrm{H}_{2} \mathrm{O}$. The molar ratio of TEOS $(x)$ was varied to $1.2,1.5,2.0$ and 2.4 . 
(C) American Chemical Society, J. Am. Chem. Soc., Supporting Info Page S-3

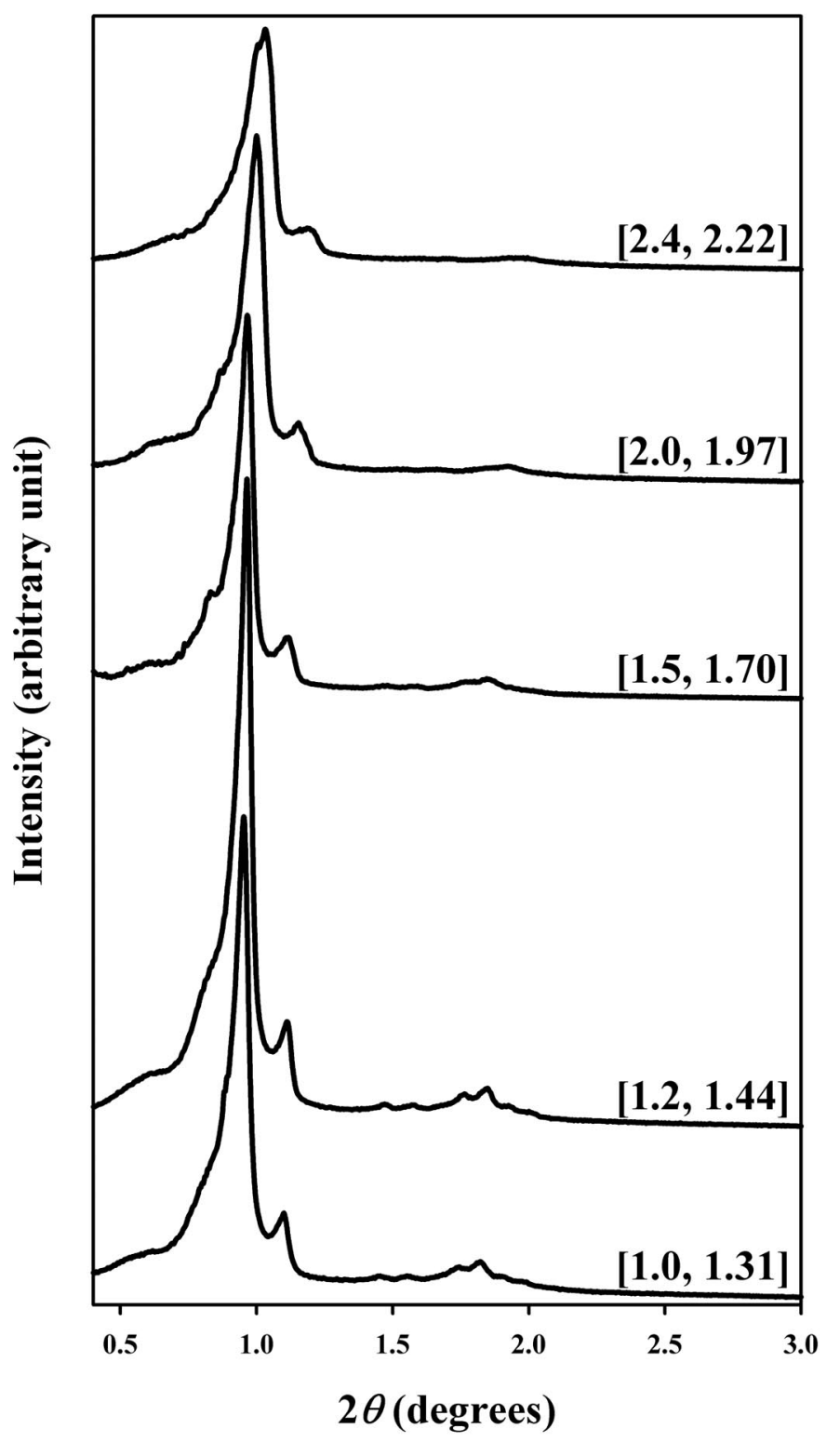

Figure S2 HRXRD patterns for the cubic $I a \overline{3} d$ mesoporous KIT-6 silicas. Each sample was prepared as the molar ratio of 0.017 P123: $x$ TEOS: $y$ BuOH:1.83 HCl:195 $\mathrm{H}_{2} \mathrm{O}$, where $[x$, y] was as shown. 
(C) American Chemical Society, J. Am. Chem. Soc., Supporting Info Page S-4

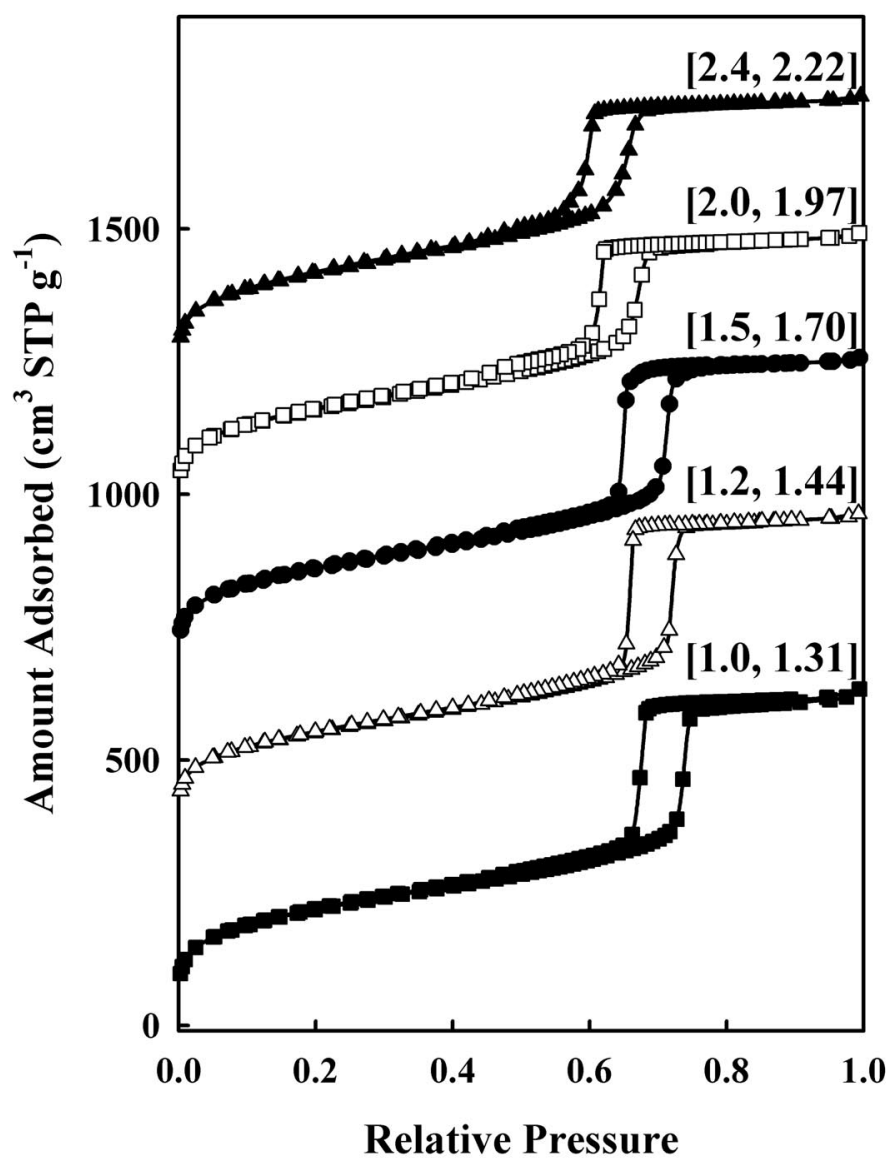

Figure $\mathbf{S 3} \mathrm{N}_{2}$ adsorption-desorption isotherms for cubic Ia $\overline{3} d$ KIT-6 silica samples. Each sample was prepared as the molar ratio of 0.017 P123: $x$ TEOS: $y \mathrm{BuOH}: 1.83 \mathrm{HCl}: 195 \mathrm{H}_{2} \mathrm{O}$, where $[x, y]$ was varied as shown. The isotherms for $[1.2,1.44],[1.5,1.70],[2.0,1.97]$ and $[2.4,2.22]$ are offset vertically by $350,650,950$, and $1200 \mathrm{~cm}^{3} \mathrm{STP} \mathrm{g} \mathrm{g}^{-1}$, respectively 
(C) American Chemical Society, J. Am. Chem. Soc., Supporting Info Page S-5

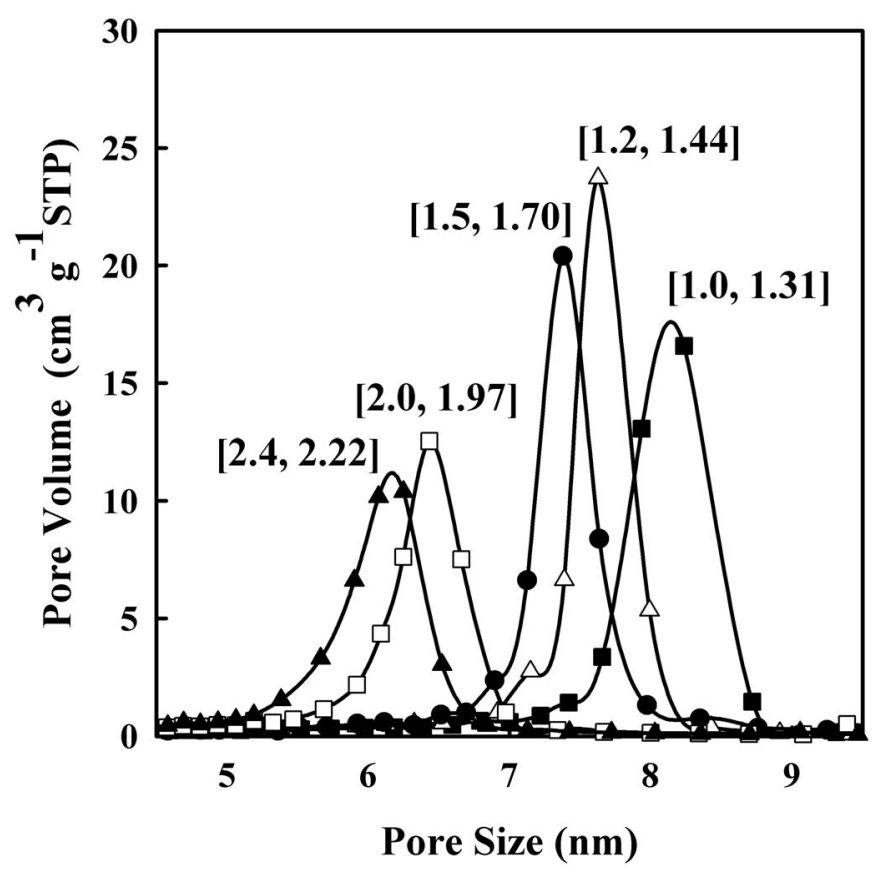

Figure S4 Pore size distributions of mesoporous $I a \overline{3} d$ KIT-6 silicas. Each sample was prepared as the molar ratio of 0.017 P123: $x$ TEOS: $y$ BuOH:1.83 $\mathrm{HCl}: 195 \mathrm{H}_{2} \mathrm{O}$, where $[x$, y] was varied as shown. 
() American Chemical Society, J. Am. Chem. Soc., Supporting Info Page S-6

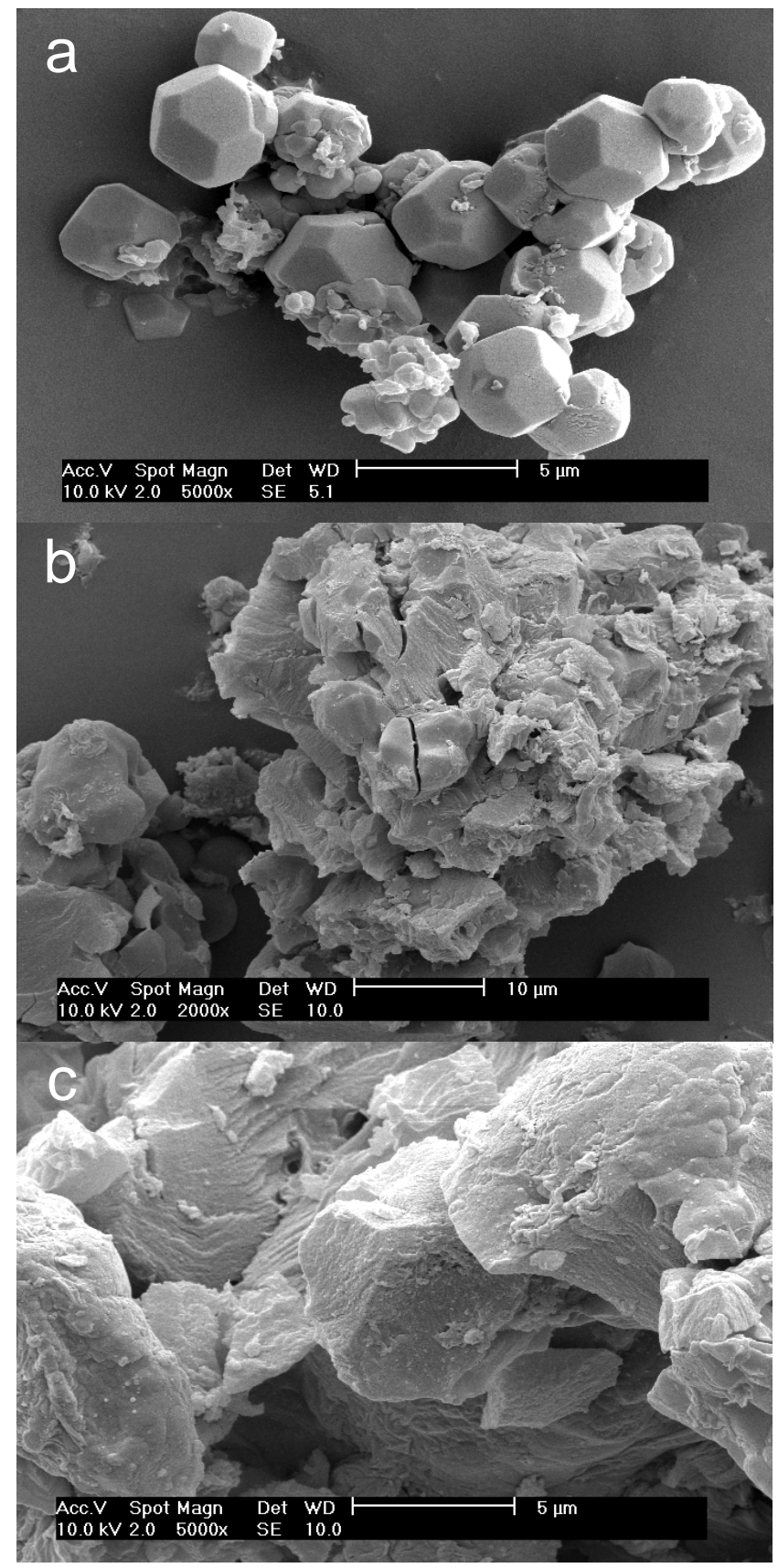

Figure S5 a) Field emission SEM image of single-crystal like MCM-48 particles synthesized according to ref. 16. b) and c) Field emission SEM images KIT-6 silica particles prepared via the structural evolution. 